\title{
Erratum to: Expression and characterization of recombinant bovine lactoferrin in $E$. coli
}

\author{
Isui García-Montoya • Susana Aideé González-Chávez • \\ Jose Salazar-Martínez • Sigifredo Arévalo-Gallegos • \\ Sugey Sinagawa-García • Quintin Rascón-Cruz
}

Published online: 26 April 2013

(C) Springer Science+Business Media New York 2013

\section{Erratum to: Biometals (2013) 26:113-122 DOI 10.1007/s10534-012-9598-7}

Due to an unfortunate turn of events, one of the co-authors names was omitted from the original publication and should have read Susana Aideé González-Chávez. The correct representation of the authors and their affiliations are listed above and below and should be treated as definitive by the reader.
The online version of the original article can be found under doi:10.1007/s10534-012-9598-7.

I. García-Montoya · S. A. González-Chávez ·

S. Arévalo-Gallegos · Q. Rascón-Cruz ( $ه)$ Laboratorio de Biotecnología, Facultad de Ciencias Químicas, Universidad Autónoma de Chihuahua, Circuito 1, Nuevo Campus Universitario,

31125 Chihuahua, Mexico

e-mail: qrascon@uach.mx

Present Address:

S. A. González-Chávez

Laboratorio PABIOM, Facultad de Medicina, Universidad Autónoma de Chihuahua, Circuito

Universitario Campus II, Chihuahua, Mexico

\author{
J. Salazar-Martínez \\ Proteo/Muu-Technologies de Mexico, Gomez Palacio, \\ Durango, Mexico \\ S. Sinagawa-García \\ Facultad de Agronomía, Campus de Ciencias \\ Agropecuarias, Universidad Autónoma de Nuevo León, \\ Monterrey, Mexico
}

